\title{
LA IMPRESCRIPTIBILIDAD DE LOS CRIMENES INTERNACIONALES: CONTORNOS, LAGUNAS Y PERSPECTIVAS
}

\author{
Non-applicability of statutory limitations of international crimes: \\ outlines, gaps and perspectives
}

Francisco Javier DONDÉ MATUTE*

\begin{abstract}
Sumario:
I. Introducción II. Breves consideraciones sobre la prescripción III. La imprescriptibilidad en los tratados internacionales IV. La imprescriptibilidad como parte del Derecho internacional de los Derechos Humanos V. La imprescriptibilidad en las jurisdicciones internacionales e hibridas VI. La imprescriptibilidad en la costumbre internacional, el ius cogens y otras consideraciones VII. La imprescriptibilidad de los crímenes internacionales en México VIII. Conclusiones
\end{abstract}

Resumen. En el presente texto se analizan y sistematizan las diferentes variables que existen en la imprescriptibilidad de los crímenes internacionales. Derivado del estudio se concluye que la imprescriptibilidad de estos crímenes no es una regla absoluta porque si bien esta figura se aplica sin reservas en los delitos establecidos en el Estatuto de Roma, en el caso de la desaparición forzada y la tortura existen menos argumentos para sustentar la imprescriptibilidad de estos tipos penales.

Palabras clave. Imprescriptibilidad, crimenes internacionales, graves violaciones a los derechos humanos, responsabilidad estatal, implementación del Derecho internacional

Abstract. In this paper the different variables in the non-statutory limitations in the international crimes are analyzed and systematized. The conclusion of the study states that the non-applicability of statutory limitations of these crimes is not an absolute rule. If this figure applies without reserves in the crimes listed by the Statute of Rome, in the case of forced disappearance and torture there are less arguments to support the statutory limitations.

Keywords Non-Statutory limitations, international crimes, grave human rights violations, state responsibility, International Law implementation

\section{Introducción}

La imprescriptibilidad de la pretensión punitiva de los crímenes internacionales es una afirmación que se da por descontada en las distintas ramas del Derecho internacional. Tan es

* Profesor-investigador en el Inacipe. Doctor en Derecho Penal y Derecho Penal Comparado (Ph.D.) por la Universidad Aberdeen Escocia. javier.donde@inacipe.gob.mx 
así que es escasa la discusión doctrinal sobre el tema ${ }^{1}$. No obstante hay diversas variables que deben considerarse en torno a la imprescriptibilidad. Entre estas variables obligan a plantear las siguientes interrogantes: ¿Cuáles crímenes internacionales son imprescriptibles? ¿En qué jurisdicción (ya sea nacional o internacional) se pueden considerar imprescriptibles los crímenes internacionales? ¿Qué diferencias o similitudes hay en la regulación de la imprescriptibilidad en el Derecho Penal Internacional (DPI) y en el Derecho Internacional de los Derechos Humanos (DIDH)? ¿Cuáles son las consecuencias de esta distinción? ¿Qué papel juega la costumbre internacional en la regulación de la imprescriptibilidad? ¿Cuál es la postura de México?

Si se analizan con detenimiento las anteriores interrogantes se podrá ver que el tema no está del todo resuelto. Es importante describir estos contornos en la regulación para estar en posibilidades de detectar lagunas y generar propuestas ante las perspectivas internacionales. Ese es el principal objetivo de este trabajo: analizar y sistematizar las variables que un Derecho internacional complejo y fragmentado presenta.

Este estudio aborda temas cuya problemática puede estudiarse desde diversas perspectivas. Para sistematizar este análisis se ha optado por agrupar distintos cuerpos normativos donde se prevé o podría preverse la imprescriptibilidad. Estos coinciden, aunque no de forma indefectible, con las distintas jurisdicciones donde se pudieran aplicar estas disposiciones.

Así, en el primer apartado se hace una breve exposición de la prescripción en materia penal. El énfasis se pone en el concepto, sus fundamentos y las repercusiones que tiene. El objetivo es simplemente fijar las bases para el tema central que es la imprescriptibilidad.

A continuación se analizaran los tratados que contienen la obligación de tipificar conductas constitutivas de crímenes internacionales; así como cualquier otro tratado internacional que establezca obligaciones para los Estados. El objeto de estudio en este primer momento lo componen los tratados con fórmulas aut dedere aut judicare. Asimismo, los tratados que prevén la obligación de establecer la imprescriptibilidad de diversos crímenes internacionales, dentro de los que figura prominentemente la Convención sobre la imprescriptibilidad de los crímenes de guerra y de los crímenes de lesa humanidad (Convención sobre Imprescriptibilidad).

En seguida se abordará el tema de la imprescriptibilidad como parte de la obligación de investigar, procesar y, eventualmente, sancionar graves violaciones a los derechos humanos. Muchos de los tratados que se analizarán en el rubro anterior están vinculados a los derechos humanos, pues consisten en graves violaciones, en este apartado se estudiará a jurisprudencia regional en la materia.

En un cuarto apartado se analizarán las disposiciones de derecho penal internacional dentro de las que protagoniza el Estatuto de la Corte Penal Internacional (ECPI, Estatuto de Roma).

\footnotetext{
${ }^{1}$ El resultado de la revisión del estado del arte no amerita una reflexión particular en este estudio, pero se ve reflejada en el aparato crítico de este trabajo. Solamente se debe aclarar que una parte considerable de los estudios tratan temas de imprescriptibilidad particulares o con base en la legislación local que no permiten hacer una extrapolación como la que pretende este estudio.

En este sentido: BIRZU, Bogdan (2015), "Considerations regarding the Non applicability of Statutory Limitations to Genocide, Crimes against Humanity and War Crimes", Acta Universitatis Danubius, Vol.11 No 3, Romania, Law Faculty of Danubius University of Galati, pp. 96-105; Villalpando, Waldo (2009), "El nuevo Derecho Internacional Penal los crímenes internacionales", Invenio, Vol 12, № 23, Argentina, Universidad del Centro Educativo Latinoamericano, pp. 15-35; CRYER, Robert et al (2007), An Introduction to International Criminal Law and Procedure, Cambridge University Press, pp. 64 y ss; Miller, Robert H. (1971), "The Convention on the Non-Applicability of Statutory Limitations to War Crimes and Crimes Against Humanity", American Society of International Law, Vol. 65, № 3, pp. 476-501; Gover, Sonja C. (2010), The European Court of Human Rights as a Pathway to Impunity for International Crimes, Canadá, Springer, pp. 231 y ss.
} 
De igual manera, las disposiciones de los demás instrumentos internacionales que establecen jurisdicciones internacionales o híbridas.

Hasta este momento se analizarán principalmente tratados internacionales; sin embargo, para cumplir con el objetivo principal de este trabajo de establecer los alcances de la imprescriptibilidad se estudiará el alcance del derecho consuetudinario es este tema, sobre todo enfatizando la posibilidad de que se llenen lagunas que hayan dejado desatendidos los tratados internacionales. Se aprovechará este espacio para considerar otros factores y hacer reflexiones sobre el alcance no convencional de la imprescriptibilidad.

Por último se realizará un análisis de la postura que ha tomado México con respecto a la imprescriptibilidad.

\section{Breves consideraciones sobre la prescripción}

En este apartado se expondrán algunas de las consideraciones sobre la prescripción. La utilidad de este esbozo es contextualizar la utilidad o necesidad de la imprescriptibilidad a nivel internacional.

De entrada debe señalarse que en estricto sentido los delitos no prescriben. La prescripción se cataloga por la doctrina como una causa de extinción de la responsabilidad penal. Cuando se habla de la misma se hace alusión al hecho de que ha pasado un tiempo determinado sin que éste sea juzgado. Por su parte, también puede aplicarse a la pena, cuando ya hay sentencia condenatoria, pero ésta no se ha cumplido2. Lo que prescribe es la pretensión punitiva, pero se habla de que recae en el delito ya que el referente para hacer el cálculo en el paso del tiempo es la punibilidad asignada por las legislaciones penales ${ }^{3}$.

En el derecho penal internacional no se habla de la prescripción de la pena, pues hasta el momento no se ha incorporado a ninguna fuente de derecho internacional. Igualmente, no parece haber casos registrados en los que se dé dicho supuesto, pues la preocupación es que los crímenes internacionales no sean impunes. Cuando prescribe la pena esto no es posible porque ya hay una sentencia condenatoria, por ello no se puede hablar de impunidad.

Al revisar el fundamento de la prescripción, hay cierta unanimidad en señalar que se justifica ante la falta de necesidad de la pena o por la dificultad que representa encontrar pruebas y desahogarlas cuando ha pasado mucho tiempo ${ }^{4}$.

En razón de la necesidad de la pena se ha dicho que:

Ello influye en la desaparición de la necesidad de la pena, que en ambas clases de prescripción se produce, por lo demás, cuando se oscurece o apaga el recuerdo del delito y el sentimiento de alarma que en su día pudo producir, y el tiempo transcurrido ocultándose de la Justicia y con la amenaza pendiente de la pena parece ya suficiente castigo - todo ello puede hacer innecesaria la prevención general_-, especialmente si el delincuente no ha vuelto a delinquir,

\footnotetext{
2 Véase Mir Puig, Santiago (2011), Derecho Penal - Parte General, Barcelona, Editorial Reppertor, p. 773.

3 Ibídem, pp. $774-5$.

${ }^{4}$ Idem.
} 
tal vez demostrando una verdadera reinserción social - lo que eliminaría la necesidad de prevención especial ${ }^{5}$.

Es importante mencionar el énfasis en la prevención que hace la doctrina del derecho penal; ya que cuando se habla de la imprescriptibilidad de los crímenes internacionales se argumenta la prevención general positiva. En otras palabras, la amenaza de que siempre se investigará a las personas que pudieran haber cometido crímenes internacionales ${ }^{6}$.

Es importante notar que la Corte Europea de Derechos Humanos ha considerado que la prescripción es un derecho humano pues favorece la seguridad jurídica y los derechos de defensa. En concreto, sería violatorio del debido proceso suponer que una persona sería condenada con pruebas que se han desvanecido con el paso del tiempo ${ }^{7}$. Podría agregarse que se ve afectado el derecho a la defensa ante la dificultad de rebatir las pruebas presentadas por la parte acusadora o presentar pruebas de descargo ${ }^{8}$.

Aunque poco se ha escrito sobre la prescripción en materia penal, en este breve apartado se establecen las bases del concepto, su fundamento y las repercusiones que tiene'. Éstas son importantes para tener una base y explorar la imprescriptibilidad en los crímenes internacionales.

\section{La imprescriptibilidad en los tratados internacionales}

En este apartado se analizaran los tratados que establecen una obligación de establecer la imprescriptibilidad de los crímenes internacionales en el derecho nacional de los Estados parte.

El instrumento internacional más remoto que contiene una orden de imprescriptibilidad es la Ley No. 10 del Consejo de Control Aliado, órgano que estableció el plan de gobierno en Alemania durante la ocupación después de la Segunda Guerra Mundial, data de 1945. Esta ley establecía las bases para procesar a personas por crímenes internacionales con base en los criterios establecidos por el Tribunal Militar Internacional de Núremberg (Tribunal de Núremberg). En su artículo II (5) establecía la imprescriptibilidad de los crímenes cometidos entre el 30 de enero de 1933 y el 1 julio de 1945. No se encuentra disposición similar en la propia Carta del Tribunal de Núremberg, pues no se consideraba que las disposiciones de prescripción nacionales fueran aplicables. Sin embargo, señalaba que los juicios basados en la legislación mencionada se llevarían a cabo por tribunales nacionales, por lo que se podría alegar la aplicación de las disposiciones de prescripción previstas en las distintas jurisdicciones ${ }^{10}$.

El tratado marco en esta materia es la Convención sobre Imprescriptibilidad de 1968, la cual consta de cuatro artículos operativos. El primer artículo establece la imprescriptibilidad de diversos crímenes de guerra y de lesa humanidad cualquiera que haya sido la fecha en la que se

5 Ibídem, p. 773. Véase también Roxin, Claus (1997), Derecho Penal - Parte General, Tomo I, Diego-Manuel Luzón Peña, Miguel Diaz y García Conlledo y Javier de Vicente Remesal (trads.), Madrid, Thomson / Civitas, p. 991.

6 Véase Amвоs, Kai (2013), Treatise on International Criminal Law, Vol. I - Foundations and General Part, Oxford, Oxford University Press, p. 430.

7 Véase Cöeme and others vs. Belguim, Application Nos. 32492/96, Judgement, párr. 145.

8 Véase ZAHAR, Alexander y Sluiter, Göran (2008), Intenational Criminal Law, Oxford, Oxford University Press, p. 517 .

9 Véase Vela Treviño, Sergio (1990), La prescripción en materia penal, $2^{\circ}$ edición, México, Trillas.

${ }^{10}$ Véase Sch аваs, William (2008), “Article 29", en: Commentary on the Rome Statute of the International Criminal Court, (Otto Triffterer ed) $2^{\text {a }}$ Edición, C.H. Beck/Hart/Nomos, p. 845. 
hayan cometido ${ }^{11}$. Esta frase se cita dado que es la que más controversia ha generado, porque implica la aplicación retroactiva del tratado ${ }^{12}$.

El primer aspecto que causa inquietud es el contenido material de la Convención sobre Imprescriptibilidad; ya que el referente de los crímenes de guerra es la Carta del Tribunal de Núremberg y las infracciones graves a los Convenios de Ginebra de $1949^{13}$. Igualmente, los crímenes de lesa humanidad que deberán considerarse imprescriptibles son los previstos en la propia Carta del Tribunal de Núremberg, agregando solamente la expulsión por ataque armado u ocupación, el Apartheid y el genocidio ${ }^{14}$.

Para efectos de este estudio es importante notar que en ambos casos la redacción es contundente pues utiliza la frase Los crímenes de guerra según la definición dada en el Estatuto del Tribunal Militar Internacional de Núremberg y Los crímenes de lesa humanidad cometidos tanto en tiempo de guerra como en tiempo de paz, según la definición dada en el Estatuto del Tribunal Militar Internacional de Núremberg.

Adicionalmente, se incluyen disposiciones que incluyen a los jefes de Estado que directamente cometan estas conductas o las toleren o a los que participen de cualquier forma en la comisión de los crímenes internacionales mencionados a través de la complicidad, la incitación o la conspiración ${ }^{15}$.

De igual forma, se establece la obligación de extraditar a las personas acusadas de cometer estos crímenes ${ }^{16}$.

Por último, los Estados parte se obligan a dejar sin efecto cualquier disposición de derecho interno que establezca la prescripción de los crímenes internacionales mencionados ${ }^{17}$.

La Convención sobre Imprescriptibilidad tiene diversos problemas comenzando con su bajo nivel de aceptación, dado que a la fecha solamente cuenta con 55 ratificaciones ${ }^{18}$. Pero lo más grave es que en el siglo XXI solamente se han registrado 13 ratificaciones lo cual hace pensar que se ha perdido interés en el tema.

La doctrina ha notado que una de las razones por las cuales la Convención sobre Imprescriptibilidad no ha tenido mucho éxito es por el hecho de que el artículo I, con la frase que se citó, abre la posibilidad a la aplicación retroactiva ${ }^{19}$. Ciertamente, esa fue la preocupación de México, pues se estableció una declaración interpretativa la cual pretende que la aplicación del tratado

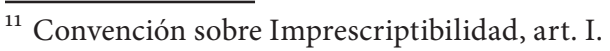

${ }^{12}$ Véase Der Wyngeart, Christine Van y Dugard, John (2002), "Non-Application of Statute of Limitations" en: The Rome Statute of the International Criminal Court: A Commentary, Vol. I (Antonio Cassese, Paola Gaeta, John R.W.D. Jones, eds), Oxford, pp. 874 - 5.

${ }^{13}$ Convención sobre Imprescriptibilidad, art. I (Dugard a).

${ }^{14}$ Ibid, art. I (b); véase Der Wyngeart Christine Van y, John op. cit, nota 12, pp. 874 - 5. (La razón por la cual se limitó el alcance temporal de este tratado se debe a que algunos de los crímenes cometidos durante el régimen Nazi estaban por prescribir, por lo que se buscó que los Estados no utilizaran esto como pretexto para no continuar con la búsqueda e investigación de estas conductas.)

${ }^{15}$ Convención sobre Imprescriptibilidad, art II.

${ }^{16} \mathrm{Ibid}$, art. III.

17 Ibid, art. IV.

${ }^{18}$ Véase Miller H. Robert (1971), “The Convention on the Non-Applicability of Statutory Limitations to War Crimes and Crimes Against Humanity”, The American Journal of International Law, Vol. 65, No. 3, p. 477. (El único consenso que se alcanzó es que las conductas previstas deberían de ser procesadas; sin embargo hubo poco interés en tratado en términos generales.)

${ }^{19}$ Ibídem, pp. $476-77$.
} 
sea claramente prospectiva, invocando la irretroactividad penal previsto en la Constitución Federal $^{20}$.

No obstante, un dato muy poco estudiado es el tema de los crímenes internacionales considerados como imprescriptibles. Dado que la Convención sobre Imprescriptibilidad data de 1968 , no da cuenta de los avances y del desarrollo que ha experimentado el derecho penal internacional. A partir de la década de los 9o's se ha verificado un crecimiento normativo enorme en esta rama del derecho. Las Naciones Unidas crearon dos tribunales penales internacionales, además de los diversos tribunales híbridos en los que colaboró para su formación. De manera más destacada se estableció una corte penal internacional permanente.

Así los crímenes internacionales que pudieran haberse considerado imprescriptibles han crecido exponencialmente. En el caso de los crímenes de guerra, se excluyen todas las conductas que se comenten en el contexto de un conflicto armado no internacional. En efecto, no fue hasta la 1977 donde se empezó a considerar esta posibilidad con la redacción del Protocolo Adicional II a los Convenios de Ginebra de 1949.

Si se toma como referente el artículo 8 del Estatuto de la Corte Penal Internacional (ECPI) se puede ver que, aun considerando los crímenes de guerra aplicables en los conflictos armados internacionales, el listado de conductas es mucho mayor al previsto en la Convención sobre Imprescriptibilidad.

Algo parecido sucede en el caso de los crímenes de lesa humanidad. En Núremberg, no se previeron crímenes internacionales que ahora son emblemáticos como la tortura, la desaparición forzada de personas o los crímenes de naturaleza sexual ${ }^{21}$.

El artículo II de la Convención sobre Imprescriptibilidad tampoco es de mucha utilidad, pues se enfatizan las formas de intervención de los agentes gubernamentales. Esta disposición también parece estar atrapada en el tiempo, pues es cada vez más común pensar en la comisión de crímenes internacionales por grupos armados organizados u otro tipo de organizaciones. Por ejemplo, la definición de ataque contra la población civil prevista en el ECPI establece la posibilidad de que organizaciones no estatales cometan estas conductas como parte de una política no vinculada al Estado ${ }^{22}$. Consecuentemente, el mencionado artículo II parece limitar la imprescriptibilidad a las conductas cometidas por agentes estatales.

Aunque se ha enfatizado el problema de la aplicación retroactiva de este tratado, con el paso del tiempo el problema más relevante es el de su escasa aplicación prospectiva. Con el paso del tiempo los casos del pasado serán cada vez menos y el problema de retroactividad tenderá a desaparecer; sin embargo, las lagunas a futuro continúan.

Esta situación tiene diversas soluciones posibles. La primera sería aumentar la lista de crímenes internacionales prevista en la Convención sobre Imprescriptibilidad. Hay antecedentes de esto, a la Convención de las Naciones Unidas contra la Delincuencia Organizada Transnacional del año 2000 se le agregaron tres protocolos para aumentar la lista de conductas consideradas como actividades de la delincuencia organizada entre el 2000 y 2001. Sin embargo, para el caso de los crímenes internacionales no parece haber mucho interés en ampliar el listado. Como ya

\footnotetext{
${ }^{20}$ Véase UNITED NATIONS (1968), Convention on the non-applicability of statutory limitations to war crimes and crimes against humanity, Treaty Collection, [en línea], disponible en: //treaties.un.org/Pages/ViewDetails. aspx?src=IND\&mtdsg_no=IV-6\&chapter=4\&lang=en (consulta 2 de mayo de 2018).

${ }^{21}$ Véase ECPI, art. 7.

${ }^{22}$ Véase art. 7 (2)

CienCIA JURÍDICA. Departamento de Derecho. División de Derecho, Política y Gobierno, Universidad de Guanajuato - Año 7, No. 13, 2018
} 
se mencionó, en el presente siglo solamente hay 13 ratificaciones, por lo que no parece haber mucha preocupación sobre el tema.

Esta falta de interés por parte de los Estados se evidencia también en tratados más modernos. Solamente las convenciones contra la desaparición forzada de personas prevén algún tipo de disposición al respecto ${ }^{23}$.

El artículo VII de la Convención interamericana sobre desaparición forzada de personas de 1994 establece lo siguiente:

La acción penal derivada de la desaparición forzada de personas y la pena que se imponga judicialmente al responsable de la misma no estarán sujetas a prescripción.

Sin embargo, cuando existiera una norma de carácter fundamental que impidiera la aplicación de lo estipulado en el párrafo anterior, el período de prescripción deberá ser igual al del delito más grave en la legislación interna del respectivo Estado Parte.

Por su parte, el artículo 8 de la Convención Internacional para la protección de todas las personas contra las desapariciones forzadas señala:

Sin perjuicio de lo dispuesto en el artículo 5 ,

1. Cada Estado Parte que aplique un régimen de prescripción a la desaparición forzada tomará las medidas necesarias para que el plazo de prescripción de la acción penal:

a) Sea prolongado y proporcionado a la extrema gravedad de este delito;

b) Se cuente a partir del momento en que cesa la desaparición forzada, habida cuenta del carácter continuo de este delito.

2. El Estado Parte garantizará a las víctimas de desaparición forzada el derecho a un recurso eficaz durante el plazo de prescripción.

Estas disposiciones se transcriben dado que no son muy comunes en el ámbito internacional y por la trascendencia al presente estudio. Como se puede observar, no hay una obligación internacional contundente para declarar la imprescriptibilidad de la desaparición forzada de personas. La Convención Interamericana empieza con una afirmación muy firme, pero matiza considerablemente la obligación permitiendo a los Estados parte establecer periodos prolongados de prescripción.

La Convención Internacional ni siquiera prevé la imprescriptibilidad, solamente establece la regla de que los tiempos sean prolongados y que empiecen a contar a partir de la aparición de la persona que es cuando cesa la desaparición forzada.

La remisión al artículo 5 es interesante pues en ese precepto se establece que cuando la desaparición forzada forma parte de una práctica generalizada o sistemática será considerada como un crimen de lesa humanidad y por lo tanto entraña[rá] las consecuencias previstas por el derecho internacional aplicable.

$\mathrm{Al}$ vincular ambos preceptos pareciera que para quienes redactaron este tratado los crímenes de lesa humanidad son imprescriptibles. En otras palabras, esta sería una de las consecuencias de considerar la desaparición forzada como un crimen de lesa humanidad. También puede

${ }^{23}$ Véase Der Wyngeart, Christine Van y Dugard, John (2002), op.cit., nota 12, pp. 878. 
afirmarse que la desaparición forzada aislada (es decir que no es cometida como parte de una práctica) no es imprescriptible.

Esta remisión parece ser una alusión a la Convención sobre Imprescriptibilidad pues es el único tratado universal que obliga a los Estados a establecer la imprescriptibilidad de los crímenes de lesa humanidad. Entonces pareciera que es una forma de ampliar el catálogo de crímenes de lesa humanidad para incluir la desaparición forzada de personas mediante la remisión genérica de derecho internacional aplicable. Dicho de otra manera, cualquier Estado parte de ambos tratados, en automático, estaría obligado a considerar la desaparición forzada de personas como imprescriptible cuando se comente en el contexto de un crimen de lesa humanidad.

Es sin duda una fórmula muy interesante de ampliar el catálogo de la Convención sobre Imprescriptibilidad de forma indirecta, pero solamente sería válida para cualquiera de los 55 Estados parte, ya que para el resto este tratado no sería parte del derecho internacional aplicable.

Una vez analizados los tratados de carácter universal ${ }^{24}$ es importante mencionar el único específico de la materia con alcance regional: Convención Europea sobre la Imprescriptibilidad de los Crímenes contra la Humanidad y de los Crímenes de Guerra (Convención Europea sobre Imprescriptibilidad). Es importante mencionar este tratado porque busca remediar algunas de las objeciones a la Convención sobre Imprescriptibilidad.

En primer término, tiene un alcance prospectivo con una fórmula prevista en los artículos 1 (3) y 6, que deben interpretarse conjuntamente. De entrada, este tratado prevé el mismo listado de crímenes internacionales previstos en la Convención sobre Imprescriptibilidad; sin embargo, el primer precepto señalado agrega que será considerada imprescriptible cualquier otra violación a una regla de costumbre internacional no prevista en el tratado. Sin embargo, el artículo 6 exige que el Estado que considere que hay alguna otra conducta que debe ser considerara como un crimen internacional imprescriptible debe hacer una declaratoria en ese sentido. Aunque la fórmula parece algo complicada de que se actualice en la práctica, por lo menos se busca aminorar una de las deficiencias más palpables de la Convención sobre Imprescriptibilidad.

De forma similar, el artículo 2 claramente elimina cualquier opción de aplicación retroactiva al señalar que la Convención Europea sobre Imprescriptibilidad solamente tiene efectos después de su entrada en vigor o a aquellos crímenes internacionales que aún no hayan prescrito en ese momento.

Aunque se trataron de establecer estos incentivos para los Estados que no optaron por ratificar la Convención sobre Imprescriptibilidad ${ }^{25}$, a la fecha este tratado solamente cuenta con 8 ratificaciones ${ }^{26}$. Por lo mismo, no se encontraron datos que indiquen que algún Estado haya presentado una declaración ampliando el catálogo de crímenes internacionales sujetos a la regla de imprescriptibilidad.

\footnotetext{
${ }^{24}$ Tales como la Convención sobre Imprescriptibilidad, la Carta del Tribunal de Núremberg, y el Estatuto de la Corte Penal Internacional.

${ }^{25}$ Véase Explanatory Report to the European Convention on the Non-Applicability of Statutory Limitation to Crimes against Humanity and War Crimes, European Treaty Series No. 82, Estrasburgo, 25 enero 1974.

${ }^{26}$ Véase Council of Europe, Chart of signatures and ratifications of Treaty o82, Treaty Office, [en línea], disponible en: https://www.coe.int/en/web/conventions/full-list/-/conventions/treaty/o82/signatures?pauth =7Qm5vTAn (consulta 2 de mayo de 2018).
} 


\section{La imprescriptibilidad como parte del Derecho internacional de los Derechos Humanos}

En este apartado se sigue abordando el tema de las obligaciones de los Estados en materia de imprescriptibilidad; sin embargo, no como parte de una obligación derivada de los tratados internacionales que directamente establecen el deber de tipificar diversas conductas; sino como una herramienta de combate a la impunidad por violaciones graves a los derechos humanos ${ }^{27}$.

La Corte Europea de Derechos Humanos ha abordado el tema en contadas ocasiones y no lo ha hecho variando la percepción tradicional de una aplicación amplia de las medidas de imprescriptibilidad. En casos de tortura ha señalado que se trata de un crimen imprescriptible ${ }^{28}$. Lo mismo ha ocurrido en los casos de conductas que constituyen crímenes de lesa humanidad ${ }^{29}$, incluso permitiendo una aplicación retroactiva de la norma como lo establece la Convención sobre Imprescriptibilidad ${ }^{30}$. Lo mismo se ha establecido en los casos de crímenes de guerra ${ }^{31}$.

La Corte Interamericana de Derechos Humanos (CorteIDH) ha tenido oportunidad de profundizar más sobre el tema. El primer pronunciamiento sobre imprescriptibilidad se encuentra en el caso Barrios Altos, en la que se estableció genéricamente que:

Esta Corte considera que son inadmisibles las disposiciones de amnistía, las disposiciones de prescripción y el establecimiento de excluyentes de responsabilidad que pretendan impedir la investigación y sanción de los responsables de las violaciones graves de los derechos humanos tales como la tortura, las ejecuciones sumarias, extralegales o arbitrarias y las desapariciones forzadas, todas ellas prohibidas por contravenir derechos inderogables reconocidos por el Derecho Internacional de los Derechos Humanos ${ }^{32}$.

El caso anterior tuvo como base una masacre perpetrada por agentes del Estado, en un contexto de represión masiva ${ }^{33}$, por lo cual no generó mucha controversia que se rechazara la prescripción de los delitos como una forma de fomentar la impunidad. No obstante, como se puede observar de la transcripción, la mención hecha por la CorteIDH es parte del dictum de la sentencia, pues el tema central fue la compatibilidad de las leyes de amnistía con la Convención Americana de Derechos Humanos ${ }^{34}$.

El tema siguió vigente en el caso Bulacio donde se aplicaron los mismos principios invocados en Barrios Altos a una detención seguida de la muerte de la víctima ${ }^{35}$, pero sin que se actualizara el contexto de represión y las autoamnistias que caracterizaron a esta sentencia. Se

\footnotetext{
${ }^{27}$ Véase PARRA, Oscar (2012), "La jurisprudencia de la Corte Interamericana respecto a la lucha contra la impunidad: algunos avances y debates”, Revista jurídica de la Universidad de Palermo, Año 13, No ${ }_{1}$, pp. 5-51; DondÉ Matute, Javier (2010), "El concepto de impunidad: leyes de amnistía y otras formas estudiadas por la Corte Interamericana de Derechos humanos", en: Sistema Interamericano de Protección de los Derechos humanos y Derecho Penal Internacional, Vol. II, Montevideo, Konrad Adenauer Stiftung, pp. 263 y ss.

${ }^{28}$ Véase ECtHR, Abdülsament Yaman v. Turkey. European Court of Human Rights, Application no. 32446/96, 2 November 2004, párr 55; ECtHR, Mocanu and others v. Romania, Applications nos. 10865/09, 45886/07 and 32431/o8. 17, September 2014, pp. 326, 346.

${ }^{29}$ Véase ECtHR, Korbely v. Hungary. Application no. 9174/02, 19 September 2008, paras. 58 y 76.

${ }^{30}$ Véase ECtHR, Kolk and Kislyiy v. Estonia (dec.), Application no. 23052/o4 by August Kolk, pp. 9-10

${ }^{31}$ Véase ECtHR, Kononov c. Lettonie, Requête no 36376/o4, 17 mai 2010, paras. 228-233.

${ }^{32}$ CorteIDH, Caso Barrios Altos vs Perú. Fondo. Sentencia de 14 de marzo de 2001, párr. 41

${ }^{33}$ Ibídem, párr. 2.

34 Véase CorteIDH, Caso Barrios Altos vs Perú. Fondo. Sentencia de 14 de marzo de 2001, párr. 44 y 44.

35 CorteIDH, Bulacio vs. Argentina. Fondo, reparaciones y costas. Sentencia de 18 de septiembre de 2003, párrs. 116-119.
} 
adoptó una aplicación genérica de este principio a cualquier violación a los derechos humanos, sin importar su gravedad o contexto ${ }^{36}$.

Esta postura empezó a matizarse en el Albán Cornejo, un caso de negligencia médica ${ }^{37}$. En este asunto se señaló que la imprescriptibilidad era solamente aplicable a las graves violaciones a los derechos humanos38. Aunque no ha quedó claro cuáles serían esas violaciones graves, en La Rochela se establece que claramente se trata de casos de genocidio, crímenes de guerra y crímenes de lesa humanidad ${ }^{39}$.

Esta postura parece incontrovertible, pero no aclara si violaciones graves, pero aisladas, estarían sujetas al régimen de excepción de la imprescriptibilidad ${ }^{40}$. Suponer que la tortura y la desaparición forzada de personas, cuando se comenten de forma aislada son imprescriptibles implicaría ir en contra del texto de los tratados regionales en la materia. En este sentido puede interpretarse la sentencia en el caso Trujillo Oroza, en la que no se defiende la imprescriptibilidad de la desaparición forzada de personas, pero si la inclusión de plazos prolongados para computar la prescripción, como en el caso concreto donde se defendió la idea de que los plazos empiezan a correr desde que la persona en encontrada ${ }^{41}$.

La CorteIDH dio un cambio de postura pronunciado en Bueno Alves, al señalar que la tortura pudiera prescribir: la Corte concluye que las autoridades judiciales, cuando analicen la posible prescripción de un delito de tortura, dada su gravedad, deben declarar dicha prescripción, cuando fuere conducente, solo después de que se haya efectuado una investigación con debida diligencia ${ }^{42}$.

Este pronunciamiento abre una línea de discusión importante. De inicio puede afirmarse que la imprescriptibilidad de la tortura ya no es absoluta. Aunque no lo dijo el tribunal en esta ocasión, siguiendo los criterios de La Rochela, esto no sería aplicable cuando la tortura constituya un crimen de lesa humanidad. Sin embargo, pudiera ser aplicable a casos de desaparición forzada, ejecuciones extrajudiciales u otras violaciones graves a los derechos humanos cometidas de forma aislada.

El criterio de debida diligencia hace depender la prescripción de criterios procesales. Como se verá en el apartado siguiente, esta frase parece aludir a casos de cosa juzgada fraudulenta o de interés de la justicia en el contexto del ECPI. En estos casos lo importante no es que el crimen internacional prescriba o no, sino que la investigación y el proceso sean legítimos o, utilizando el lenguaje del Estatuto de Roma, no se pretenda extraer a la persona de la acción de la justicia. Se busca establecer un equilibrio entre los derechos de la persona y el combate a la impunidad. Dicho de otra manera, si el Estado actúa de forma convincente en la investigación no se justifica establecer una medida como la imprescriptibilidad que puede dañar el derecho de defensa.

\footnotetext{
${ }^{36}$ Véase Ídem.

37 CorteIDH, Caso Albán Cornejo y otros vs. Ecuador, Fondo, reparaciones y costas. Sentencia de 22 de noviembre de 2007 , párr. 2.

${ }^{38}$ Ibídem, párr. 111.

39 CorteIDH, Caso de la Masacre de La Rochela vs. Colombia. Fondo, reparaciones y costas. Sentencia de 11 de Mayo de 2007, párr. 291; véase también CorteIDH, Vera Vera y otra vs. Ecuador. Excepción preliminar, fondo, reparaciones y costas. Sentencia de 19 de mayo de 2011, párrs. 117, 118 y 120

${ }^{40}$ Véase CorteIDH, Caso Albán Cornejo y otros vs. Ecuador, op. cit. nota 37, párr. 30.

${ }^{41}$ Véase CorteIDH, Trujillo Oroza vs. Bolivia. Reparaciones y costas. Sentencia de 27 de febrero de 2002, párr. 72.

${ }^{42}$ Véase CorteIDH, Bueno Alves vs Argentina. Supervisión de cumplimiento de sentencia. Resolución de 5 de julio de 2011, párr. 45. (Cursivas del autor)
} 


\section{La imprescriptibilidad en las jurisdicciones internacionales e híbridas}

En este apartado se abandona parcialmente el énfasis en las jurisdicciones nacionales para abordar la imprescriptibilidad en las jurisdicciones internacionales, representadas por los tribunales penales para la antigua Yugoslavia y para Ruanda (tribunales ad hoc) y, por supuesto, la Corte Penal Internacional (CPI).

En los tribunales ad hoc el tema de la imprescriptibilidad está ausente en los estatutos. En la práctica esto no generó un problema ya que como los conflictos que dieron origen a estos órganos jurisdiccionales fueron próximos temporalmente a su creación no hubo casos en los cuales se presentara un caso de prescripción. Si esta fue la razón por la cual no se incluyó la imprescriptibilidad de los crímenes internacionales o si esto se debió a la falta de consenso entre los miembros del Consejo de Seguridad que crearon estos tribunales es difícil de establecer dado que no hay registro alguno en los antecedentes normativos o en las resoluciones correspondientes.

No obstante, en el Reporte del Secretario General de las Naciones Unidas correspondiente a la creación del Tribunal Penal Internacional para la antigua Yugoslavia, se muestra una clara preocupación por respetar el principio de legalidad, por lo que solamente se incluyeron crímenes internacionales que más allá de toda duda formaban parte del Derecho internacional al momento de su comisión, ya sea en virtud del derecho convencional o del derecho consuetudinario ${ }^{43}$.

En virtud de que esta es la misma preocupación que ha sido invocada como un obstáculo para la ratificación de la Convención sobre Imprescriptibilidad y que trató de resolverse con la Convención Europea ${ }^{44}$ pudiera pensarse que lo mejor era no generar mayor controversia omitiendo el tema.

El tema empieza a cambiar con los tribunales híbridos, excepción hecha de la Corte Especial para Sierra Leona cuyo estatuto no regula la prescripción ${ }^{45}$.

Cronológicamente, el primer caso que se puede analizar es el de Timor Oriental, donde la administración transitoria de la Naciones Unidas estableció paneles encargados de aplicar el Derecho penal internacional durante el movimiento independentista ${ }^{46}$.

De conformidad con la regulación aplicable, el genocidio, los crímenes de guerra, crímenes de lesa humanidad y tortura son imprescriptibles ${ }^{47}$. Por su parte, los delitos de homicidio y aquellos de naturaleza sexual de conformidad con el Código Penal de Timor Oriental no son considerados, por lo que aplica la legislación local en la materia ${ }^{48}$. Es clara la distinción entre

\footnotetext{
${ }^{43}$ Véase Report of the secretary-general pursuant to paragraph 2 of security council resolution 808 (1993), Presented 3 May 1993 (S/25704), parrs $33-36$.

44 Véase apartado III supra.

45 Véase Swart, Bert (2004), "Internationalized Courts and Substantive Criminal Law”, en: Internationalized Criminal Courts - Sierra Leone, East Timor, Kosovo and Cambodia, (Cesare P.R. Romano, André Nollkaemper and Jann K. Kleffner eds.), International Courts and Tribunals Series, Oxford University Press, pp. 312 - 313. (En los tribunales híbridos es importante la competencia temporal para determinar si la imprescriptibilidad es relevante. Entre más amplia la competencia temporal y entre más remotos los hechos más importante se vuelve el establecer la imprescriptibilidad.)

${ }^{46}$ Véase Regulation no. 2000/15 on the establishment of panels with exclusive jurisdiction over serious criminal offences, 6 June 2000.

47 Ibídem, sec. 17.1.

${ }^{48}$ Ibídem, sec. 17.2.
} 
aquellos delitos del orden nacional, los cuales están sujetos a términos de prescripción, y los crímenes internacionales que son imprescriptibles.

Es importante mencionar que el homicidio puede ser considerado como genocidio ${ }^{49}$, crimen de lesa humanidad ${ }^{50}$ o crimen de guerra ${ }^{51}$ si se dan las circunstancias especiales de cada caso. Los crímenes internacionales pueden implicar conductas de naturaleza sexual; si bien no exclusivamente, se hace expreso en el caso de los crímenes de lesa humanidad ${ }^{52}$.

Destaca el caso de la tortura, pues independiente de que sea un crimen de lesa humanidad o se cometa de forma aislada se considera imprescriptible ${ }^{53}$. Esto contrasta con las convenciones en la materia que no establecen la regla de imprescriptibilidad para esta conducta.

Por otro lado, también es importante mencionar la imprescriptibilidad en el caso de las Salas Extraordinarias en los Tribunales de Camboya, tribunal híbrido cuyo objetivo era procesar a los posibles responsables del genocidio en ese país durante de 1975 a $1979^{54}$. En la ley correspondiente destaca también la distinción entre delitos nacionales y crímenes internacionales, pero con algunas diferencias. El genocidio ${ }^{55}$ y los crímenes de lesa humanidad 56 también son considerados imprescriptibles. Sin embargo, el precepto que regula los crímenes de guerra no establece que dichas conductas sean imprescriptibles; destaca el hecho de que varias son violaciones graves a los convenios de Ginebra de $1949^{57}$.

Por su parte, los delitos considerados como nacionales: homicidio, tortura y persecución religiosa tienen un periodo de prescripción, adicional al previsto en el código penal nacional de $30 a^{n} o^{58}$. Es importante destacar que la tortura está prevista en este tribunal híbrido como un delito nacional, por lo que a diferencia de la jurisdicción de Timor Oriental está sujeta a plazos de prescripción, aunque bastante prolongados.

El caso de la CPI es mucho más contundente ${ }^{59}$. El artículo 29 no deja lugar a interpretación: Los crímenes de la competencia de la Corte no prescribirán. Dichos crímenes son genocidio, crímenes de lesa humanidad, crímenes de guerra y agresión ${ }^{60}$.

El problema es que el artículo 1 es igualmente contundente al señalar que el ECPI establece una jurisdicción internacional distinta a las nacionales, con quienes tiene una relación comple-

\footnotetext{
49 Ibídem, sec. 4 (a).

${ }^{50}$ Ibídem, sec. 5.1 (a)

${ }^{51}$ Ibídem, sec. 6.1 (a) (i); (b) (iv), (xi); (c) (i).

${ }^{52}$ Ibídem, sec. 5.1. (g).

53 Ibidem, sec. 5.1 (f) y sec. 7.

${ }^{54}$ Law on the Establishment of the Extraordinary Chambers, with inclusion of amendments as promulgated on 27 October 2004 (NS/RKM/1004/006), art. 1.

55 Ibídem, art. 4 .

56 Ibídem, art. 5.

57 Ibídem, art. 6.

${ }^{58}$ Ibídem, art. 3. Es importante mencionar que la ley originalmente preveía un periodo adicional de 20 años, pero en 2004 se reformó para ampliarla a 30 años. Véase Meijer, Ernestine E. (2004), The Extraordinary Chambers in the Courts of Cambodia for Prosecuting Crimes Committed by the Khmer Rouge: Jurisdiction Organization, and Procedure of an Internationalized National Tribunal en Internationalized Criminal Courts - Sierra Leone, East Timor, Kosovo and Cambodia, (Cesare P.R. Romano, André Nollkaemper and Jann K. Kleffner eds.), International Courts and Tribunals Series, Oxford University Press, pp. 215 - 6. (Es cuestionable que una prescripción pueda ampliarse una vez vencido el plazo y que solamente sea aplicable para unos delitos y otros no.)

59 Cfr. Амвos, Kai (2013), op. cit., nota 6, p. 429. (Algunos crímenes de guerra no son lo suficientemente graves como para ameritar la imprescriptibilidad; por ejemplo, el uso indebido de los emblemas de la Cruz Roja); véase también Miller H., Robert (1971), op. cit. nota 18, pp. 481 y 482. (La gravedad de algunos crímenes de guerra también fue motivo de discusión en la redacción de la Convención sobre Imprescriptibilidad)

${ }^{60}$ ECPI, art. 5
}

CIENCIA JuRídicA. Departamento de Derecho. División de Derecho, Política y Gobierno, Universidad de Guanajuato - Año 7, No. 13, 2018 
mentaria. Consecuentemente, la imprescriptibilidad es, en principio, solamente aplicable para la CPI y no genera obligaciones para los Estados o para los individuos ${ }^{61}$.

Un sector de la doctrina considera que la imprescriptibilidad prevista en el ECPI puede hacerse valer a través del principio de complementariedad. En otras palabras, si un Estado no investiga hechos constitutivos de los crímenes competencia de la CPI por considerarlos prescritos pudiera considerarse que se trata de un caso de falta de voluntad o de falta de capacidad, lo cual

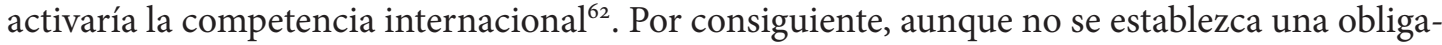
ción de considerar estos crímenes internacionales como imprescriptibles el esquema normativo prevé una consecuencia jurídica por la omisión.

El problema con este argumento es que el no investigar hechos por considerarlos imprescriptibles no está expresamente mencionado como una causal de falta de voluntad o falta de capacidad. Adicionalmente, la jurisprudencia de la CPI tampoco abona a este argumento. Al determinar la admisibilidad en el caso Saif Al - Islam Gaddafi la Sala de Cuestiones Preliminares I señaló que para este análisis no es determinante que una conducta sea considerada como un crimen internacional o no. De hecho, con base en el artículo 20 (3) del ECPI señaló que la cosa juzgada fraudulenta no se actualiza necesariamente si las investigaciones y los procesos nacionales se llevan a cabo por delitos del orden nacional. Lo importante es determinar la integridad de los procedimientos y la intensión de sustraer a la persona de la acción de la justicia penal internacional ${ }^{63}$.

Esta resolución judicial pone en entredicho el hecho de que haya una obligación de establecer la obligación de imprescriptibilidad a nivel nacional por crímenes competencia de la CPI. Si bien el asunto concreto no se abordó, la Sala de Cuestiones Preliminares consideró que no hay una obligación de modificar la legislación penal sustantiva derivada del ECPI. Aunque el análisis se centró en los tipos penales del código penal libio, nada hace suponer que lo mismo no ocurriría con la prescripción como figura de derecho penal sustantivo.

Es importante mencionar que un asunto de este tipo pudiera ventilarse aun antes de un análisis de admisibilidad. El artículo 53 (1) (c) del ECPI faculta a la Fiscalía a no iniciar una investigación si no redundaría en interés de la justicia. Dentro de los factores que la Fiscalía debe considerar para hacer esta determinación son los intereses de las víctimas y la edad del presunto autor $^{64}$. Consecuentemente, en un supuesto en el que aplica la prescripción de la pretensión punitiva, pero se deje a salvo la reparación del daño y los intereses de las víctimas podría no haber interés para iniciar la investigación internacional. Asimismo, como la prescripción opera con el

\footnotetext{
${ }^{61}$ Véase Milanovic, Marko (2011), "Is the Rome Statute Binding on Individuals (And Why Should We Care)", Journal of International Criminal Justice, Vol. 9, pp. 25 - 52. (En este estudio se trata el tema del alcance competencial que tienen el ECPI para las jurisdicciones nacionales y las personas dentro de éstas. Aunque no aborda el tema concreto de la prescripción se plantean los límites de las jurisdicciones internacionales.); Cfr. ScHABAS, William (2008), op. cit. nota 10, p. 846. (El artículo 29 es el reflejo del desarrollo del Derecho Penal Internacional en este tema.

${ }^{62}$ Véase Schabas, William (2008), op. cit. nota 10, pp. 846 - 8. Véase también Der Wyngeart, Christine Van y Dugard, John (2002), op. cit., nota12, pp. $887-8$.

${ }^{63}$ Véase Prosecutor vs Gaddafi and Al-Senussi, Decision on the admissibility of the case against Saif Al-Islam Gaddafi, Pre-Trial Chamber I, ICC-01/11-01/11, 31 Mayo 2013, parrs. 85 - 86.

64 Véase ECPI, art. 53 (2) (c).
} 
paso del tiempo la edad avanzada del presunto autor pudiera ser un factor para desistirse de la investigación en aras de que no habría interés de la justicia.

Aunque estos argumentos escapan del tema central de este trabajo, resulta claro que, en el mejor de los casos, es debatible que la imprescriptibilidad del artículo 29 del ECPI implique algún tipo de obligación para los Estados.

\section{La imprescriptibilidad en la costumbre internacional, el ius cogens y otras consideraciones}

El objetivo de este apartado es hacer un recuento de otros instrumentos internacionales extra convencionales para tratar de establecer la posibilidad de que la obligación de considerar imprescriptibles los crímenes internacionales tenga un sustento en la costumbre internacional.

Para llegar a esta conclusión es importante recordar que la formación de la costumbre internacional requiere de dos elementos: la práctica reiterada de los Estados y la consideración de esa práctica como jurídicamente vinculante (opinio iuris) ${ }^{65}$.

Entrar a esa discusión va más allá de los alcances de este estudio, por lo que se adoptará una postura tradicional en el sentido de establecer la existencia de estos dos elementos, pero a su vez, se tomará en consideración la práctica legislativa y judicial para la determinación de estos factores. En materia penal internacional las acciones de órganos no encargados estrictamente de la política exterior de un Estado son importantes, pues en este último ámbito rara vez vamos a encontrar expresiones de los poderes ejecutivos o los miembros de gabinete encargados. En otras palabras, la práctica estatal es más evidente en la promulgación de leyes y en las decisiones judiciales (sobre todo cuando son reiteradas). Estos son los factores que se considerarán para la identificación de normas de costumbre internacional.

Todo parece indicar que la Convención sobre Imprescriptibilidad no ha alcanzado el carácter de norma de costumbre internacional oponible a los Estados que no la han ratificado ${ }^{66}$. Como se mencionó en el apartado correspondiente, este tratado solamente cuenta con 55 ratificaciones y solamente 13 Estados la han ratificado en los últimos años.

El desinterés por la Convención sobre Imprescriptibilidad se acentúa con los constantes llamados de la Asamblea General de Naciones Unidas a ratificarla, sin que los Estados tengan mucho interés en hacerlo67. De hecho, la Asamblea General ha dejado de insistir en el tema, pues la última resolución es de 2008.

Sin embargo, la pregunta más relevante es ¿por qué la Convención sobre Imprescriptibilidad tiene tan pocas ratificaciones? ¿Se debe a la falta de consenso en determinar que los crímenes internacionales son imprescriptibles o a otro tipo de objeciones como la irretroactividad de la regla?

La Convención Europea sobre Imprescriptibilidad parece resolver estas preguntas, pues aunque se trataron de atender los problemas de retroactividad y falta de precisión en los crímenes

\footnotetext{
${ }^{65}$ Artículo 38 del Estatuto de la Corte Internacional de Justicia: 1. La Corte, cuya función es decidir conforme al derecho internacional las controversias que le sean sometidas, deberá aplicar: a. [...]

b. la costumbre internacional como prueba de una práctica generalmente aceptada como derecho; [...]

${ }^{66}$ Véase Ratner, Steven R. y Abrams, Jason (2001), Accountability for Human Rights Atrocities in International Law, Oxford University Press, pp. $143-145$.

67 Véase G.A. Res 2583 (XXIV); G.A. Res 2712 (XXV); G.A. Res 2840 (XXVI); G.A. Res 3020 (XXVII); G.A. Res 3074 (XXVIII).
} 
considerados imprescriptibles, a la fecha hay todavía pocas ratificaciones ${ }^{68}$. Esto habla de que hay un desinterés general por la imprescriptibilidad de los crímenes internacionales.

Ya también se ha dado cuenta de la falta de consenso e interés por considerar ciertas conductas como la desaparición forzada de personas y la tortura como crímenes imprescriptibles. Incluso en el seno del sistema interamericano de derechos humanos la obligación de considerar estas conductas como imprescriptibles se ha diluido bastante.

Ciertamente, es debatible que la ratificación de los tratados pueda tomarse como un indicador de la opinio iuris en la conformación de la costumbre internacional. Lo que es más objetivo en esta determinación es que tratados como los que buscan sancionar penalmente la desaparición forzada y la tortura ni siquiera prevén esta obligación ${ }^{69}$.

Ante la falta de consenso en los tratados internacionales un sector de la doctrina7o ha optado por apelar al ius cogens para establecer la imprescriptibilidad de ciertos crímenes internacionales. En particular, se hace referencia al dictum en la sentencia de primera instancia en el caso Furundzija del Tribunal Penal Internacional de la antigua Yugoslavia. Al hacer un recuento de la normatividad jurídico-internacional de la tortura en el Derecho internacional la sala de primera instancia señaló que hay una prohibición general en contra de la tortura, de tal forma que sería impensable suponer que los Estados pudieran permitirla en cualquier circunstancia ${ }^{71}$. La prohibición absoluta en contra de la tortura tiene ciertas consecuencias como la imprescriptibilidad $^{72}$.

Es indudable que la prohibición de la tortura es una obligación con estatus de norma de ius cogens; junto con las prohibiciones contra el genocidio, la esclavitud, la discriminación racial, la agresión, el uso ilegitimo de la fuerza por parte de los Estados y la supresión forzosa de la autodeterminación de los pueblos ${ }^{73}$. No obstante, la conclusión a la que llega la sala de primera instancia no se ve reflejada en el derecho convencional o consuetudinario internacional.

Sí bien puede hablarse de un rechazo universal a la tortura que se traduce en una obligación ius cogens para prohibirla. ¿Esta prohibición necesariamente tiene que darse a través de la vía penal? ¿Podría verse satisfecha a través de programas de prevención? ¿Se puede justificar en detrimento en otros derechos como el debido proceso y el derecho de defensa? ¿Dicha prohibición puede detallarse al grado de obligar a que la conducta sea imprescriptible?

En este estudio solamente interesa tratar de dar solución a la última pregunta planteada. Si fuera tan evidente la línea de razonamiento del Tribunal Penal Internacional para la antigua Yugoslavia no habría mayor objeción con la Convención sobre Imprescriptibilidad, ni con la inclusión de la imprescriptibilidad en los tratados multilaterales contra la tortura. Si no se alcanza el consenso en estos tratados internacionales, mucho menos se puede argumentar que la

${ }^{68}$ Cfr. Der Wyngaert, Christie Van y Dugard, John, op. cit., nota 12, p. 887. (Para estos autores la Convención sobre Imprescriptibilidad representaba el estado de la costumbre internacional al momento de su redacción. En todo caso, la retroactividad causó muchas objeciones pero la idea de considerar los crímenes internacionales previstos en la Convención sobre Imprescriptibilidad no representó mayor objeción.)

${ }^{69}$ Ibídem, p. 878. (La falta de consenso exhibida por los Estados es mucho más amplia, pues es evidente no solamente en los tratados multilaterales, sino también en los estatutos de los tribunales ad hoc e híbridos.)

70 Véase, PARra, Óscar, op. cit. nota 27, p. 29.

${ }^{71}$ Véase Prosecutor v. Furundzija, IT-95-17/1-T, Judgment, 10 December 1998, parrs. 153 - 156.

72 Ibídem, parr. 157 "It would seem that other consequences include the fact that torture may not be covered by a statute of limitations, and must not be excluded from extradition under any political offence exemption."

73 Ibídem, parr. 147. (Estos son ejemplos mencionados en la sentencia citada como obligaciones erga omnes, que pudieran constituir prohibiciones ius cogens.) 
imprescriptibilidad de la tortura es una norma de ius cogens, la cual requiere un grado de consenso mucho mayor ${ }^{74}$.

Curiosamente, en la sentencia del caso Furundzija se plantea que una de las consecuencia de que la prohibición contra la tortura sea una prohibición ius cogens es que no se considerará delito político para efectos de la extradición. Esta implicación, a diferencia de la imprescriptibilidad, si forma parte de los tratados en la materia ${ }^{75}$.

Si a esto se le agrega que la Corte Interamericana de Derechos Humanos ha matizado su postura, por lo cual la imprescriptibilidad de la tortura no es absoluta, sino que está condicionada a que se realicen las debidas diligencias en la investigación y el enjuiciamiento, entonces su carácter absoluto como norma de ius cogens queda en entredicho.

Por consiguiente, aunque la prohibición contra la tortura es una norma de ius cogens, de la misma no se puede derivar la imprescriptibilidad de este crimen internacional.

De las anteriores reflexiones se puede llegar a la conclusión de que no hay una norma de costumbre internacional consolidada, aunque sí en formación que establezca la imprescriptibilidad de algunos crímenes internacionales ${ }^{76}$. ¿Pero cuáles crímenes internacionales?

El artículo 29 del ECPI establece un buen parámetro. Si bien los Estados han mandado un mensaje muy claro al no ratificar la Convención sobre Imprescriptibilidad, también lo han hecho con el alto número de ratificaciones del ECPI, que a la fecha consta de $123^{77}$. Consecuentemente, esta incipiente norma consuetudinaria incluye el genocidio, los crímenes de lesa humanidad, los crímenes de guerra y la agresión; además con la inclusión amplia de conductas que por mucho supera a las de tratados anteriores.

Esta norma se encuentra consolidada en virtud del mencionado artículo 29 en la jurisdicción internacional y puede ser considerada como incipiente en las jurisdicciones nacionales. De hecho, varios Estados han incluido la imprescriptibilidad de los crímenes competencia de la CPI al momento de promulgar sus leyes de implementación, lo cual evidencia, a través de los diversos actos legislativos los elementos de la costumbre internacional ${ }^{78}$.

No obstante, no se puede llegar a las mismas conclusiones con respecto a otros crímenes internacionales como la desaparición forzada y la tortura (cuando se comenten de forma ais-

\footnotetext{
${ }^{74}$ Véase Convención de Viena sobre el Derecho de los Tratados, art. 53. El ius cogens se define como [...] una norma imperativa de derecho internacional general es una norma aceptada y reconocida por la comunidad internacional de Estados en su conjunto como norma que no admite acuerdo en contrario y que sólo puede ser modificada por una norma ulterior de derecho internacional general que tenga el mismo carácter.

75 Véase Convención contra la tortura y otros tratos o penas crueles, inhumanos o degradantes, art. 8; Convención Interamericana para Prevenir y Sancionar la Tortura, art. 13.

${ }^{76}$ Véase Amвоs, Kai (2013), op. cit., nota 6, p. 429.

77 Véase https://asp.icccpi.int/en_menus/asp/states\%2oparties/pages/the\%2ostates\%2oparties\%2oto\%2othe\%2O rome\%2ostatute.aspx (2 de mayo de 2018).

${ }^{78}$ Perú, Ley que Regula los Delitos Contra el Derechos internacional de los Derechos Humanos y el Derecho Internacional Humanitario, artículo 6; España, Ley Orgánica 10/1995, de 23 de noviembre, del Código Penal, artículo 131; Finlandia, The Criminal Code of Finland 39/1889, Chapter 8; Guatemala, Iniciativa que dispone aprobar la ley de implementación del Estatuto de roma de la Corte Penal Internacional, artículo 15; Paraguay, Proyecto de ley que implementa el Estatuto de Roma que crea la Corte Penal Internaciona, parr. 10; Perú, Proyecto de ley 163/2011- CR, artículo 111; Panamá, Código Penal de la República de Panamá, artículo 121; The Netherlands, Act of 19 June 2003 containing rules on grave breaches of international humanitarian law (International Crimes Act), section 21; Lithuania, Law on the approval and entry info foce of the criminal code, 26 september 2000 No. Viii-1968, artículo 95. 5; Irland, International Criminal Court Act 2006, artículo 29; Slovenia, Criminal Code (KZ-1), artículo 95; Estonia, Penal Code Passed 6 June 2001, artículo 81.2; Congo, Journal Officiel de la République Démocratique du Congo, artículo 34 bis; Croatia, Criminal Code Kazneni Zakon, artículo 24.
} 
lada) pues no hay un sustento convencional y el fundamento consuetudinario parece bastante endeble. En todo caso, se pudieran incluir como uno de los aspectos del combate a la impunidad por violaciones graves a los derechos humanos, junto con las ejecuciones sumarias, arbitrarias y extrajudiciales. Sin embargo, dicha obligación y solamente es válida en el sistema interamericano de derechos humanos y sujeta a los parámetros de "debida diligencia" que se plantaron en el apartado correspondiente.

\section{La imprescriptibilidad de los crímenes internacionales en México}

La postura del Estado Mexicano con respecto a la imprescriptibilidad de los crímenes internacionales se puede medir de tres formas distintas: respecto a los tratados internacionales de los que es parte, en relación a las leyes que se promulgado al respecto y analizando la práctica de los tribunales.

En atención al primer rubro, México es parte de la Convención sobre imprescriptibilidad desde el 22 de abril de 2002, fecha en la que se publicó en el Diario Oficial de la Federación. Cabe mencionar que dicha publicación se hizo con una declaración interpretativa en la cual se precisa que los crímenes previstos en el tratado son imprescriptibles cuando se hayan cometido con posterioridad a la entrada en vigor para México, con base en la prohibición de irretroactividad prevista en el artículo 14 de la Constitución Federal. Por su relevancia se transcribe dicha declaración del Estado Mexicano:

Con fundamento en el artículo 14 de la Constitución Política de los Estados Unidos Mexicanos, el Gobierno de México, al ratificar la Convención sobre la Imprescriptibilidad de los Crímenes de Guerra y de los Crímenes de Lesa Humanidad, adoptada por la Asamblea General de las Naciones Unidas el 26 de noviembre de 1968, entenderá que únicamente considerará imprescriptibles los crímenes que consagra la Convención, cometidos con posterioridad a su entrada en vigor para México.

Esta declaración interpretativa recoge la inquietud principal de varios de los objetores de la Convención sobre Imprescriptibilidad y quienes trataron de corregir la aplicación retroactiva de la obligación en la Convención Europea sobre Imprescriptibilidad.

Sin embargo, hay que tener presente que las imprecisiones que en su momento se hicieron notar son aplicables también para México. Es decir, la imprescriptibilidad solamente abarca los crímenes previstos en ese tratado y no el catálogo más amplio previsto en el ECPI.

Ahora bien, México reconoce la imprescriptibilidad en la jurisdicción penal internacional en virtud de la ratificación del ECPI, la cual entró en vigor el 1 de enero de 2006. Siguiendo el razonamiento del apartado anterior habría que preguntarse si México participa de la formación de costumbre internacional con su práctica legislativa y judicial.

En el plano legislativo la pregunta se resuelve con cierta facilidad ya que no hay una ley de implementación del ECPI, ni reformas para adecuar la legislación interna al derecho penal sustantivo previsto en este tratado internacional. Solamente hay dos disposiciones sobre imprescriptibilidad. La primera es la Ley General para Prevenir, Investigar y Sancionar la Tortura y otros Tratos o Penas Crueles, Inhumanos o Degradantes que establece en su artículo $8 \mathrm{El}$ 
ejercicio de la acción penal y la sanción que se imponga judicialmente para el delito de tortura son imprescriptibles.

La más reciente es la Ley General en Materia de Desaparición Forzada de Personas, Desaparición Cometida por Particulares y del Sistema Nacional de Búsqueda de Personas que en su artículo 14 prevé: El ejercicio de la acción penal y la ejecución de sanciones penales que se impongan judicialmente para los delitos de desaparición forzada de personas y de desaparición cometida por particulares son imprescriptibles y no están sujetos a criterios de oportunidad ni a formas de solución alterna al proceso u otras de similar naturaleza.

Siguiendo la lógica de la declaración interpretativa estas disposiciones sobre imprescriptibilidad no podrían aplicarse de forma retroactiva. Consecuentemente, la tortura es imprescriptible a partir del 27 de junio de 2017, día posterior a la publicación del decreto promulgatorio. Por su parte, la desaparición forzada de personas es imprescriptible solamente que se haya cometido con posterioridad al 18 de noviembre de 2017, en atención a la fecha de publicación de la ley en el Diario Oficial de la Federación.

Surge entonces la duda, ¿Qué pasa con los casos de tortura y desaparición forzada de personas cometidos con anterioridad a las fechas señaladas? Para llegar a esta respuesta es necesario hacer un análisis de la postura de la Suprema Corte de la Nación (SCJN).

La SCJN nunca ha considerado como imprescriptibles crímenes internacionales ante la ausencia de una disposición constitucional, convencional o legal clara. Aunque no ha entrado al análisis de la costumbre internacional en estos temas, de la argumentación de los casos donde se ha pronunciado no se desprende que le haya dado mayor importancia a esta fuente de derecho internacional.

En el Amparo en Revisión 140/2002 en donde se impugnó la resolución de extradición de Ricardo Miguel Cavallo a España por genocidio, terrorismo y tortura, la SCJN entró al análisis de la prescripción, lo cual no hubiera sido necesario si estas conductas (por lo menos el genocidio y la tortura) hubieran sido considerados imprescriptibles ${ }^{79}$.

Un aspecto interesante de la sentencia es que se consideró que el terrorismo y el genocidio (no así la tortura) eran crímenes permanentes, pues formaban parte del mecanismo de represión de la dictadura militar en Argentina, de tal manera que se seguían cometiendo estas conductas mientras durara el régimen. Así las conductas no cesaron de cometerse hasta 1983, por lo que hasta entonces empezó a correr el cómputo de la prescripción. La conclusión fue que el terrorismo y el genocidio no habían prescrito pero la tortura sí, por lo que se negó la extradición por este crimen ${ }^{80}$.

Hay algunos aspectos relevantes de esta sentencia. En primer lugar, la Convención sobre Imprescriptibilidad ya había entrado en vigor para México al momento del fallo que fue el 10 de junio de 2003; sin embargo no se analizó la aplicabilidad de este tratado internacional por lo que respecta al genocidio. Considerar que el término de la prescripción empieza a correr una vez que se concreta la transición democrática cuando los crímenes se pueden considerar como crímenes de Estado. Es importante señalar que el razonamiento de la SCJN no fue en el sentido de que la prescripción empieza a correr desde que es posible jurídica y fácticamente iniciar una investigación, sino que se trataba de crímenes permanentes.

El tema de la prescripción se volvió a tratar en el Recurso de Apelación 1/2003 atraído por la Primera Sala de la SCJN. Un caso de desaparición forzada de personas que fue declarado pres-

\footnotetext{
79 Véase Amparo en Revisión 140/2002, Considerando Décimo Tercero, pp. 932 - 959.

${ }^{80}$ Ibídem, pp. $959-963$. 
crito. Es importante notar que la acusación del agente del Ministerio Público fue por privación ilegal de la libertad. En este caso se adoptó la postura de que los tiempos para la prescripción deberán ser prolongados ${ }^{81}$. El razonamiento fue que este delito se termina de consumir cuando la persona es puesta en libertad, dado que se trata de un delito permanente ${ }^{82}$. El referente es la violación al bien jurídico, mientras se siga lesionando se sigue cometiendo el delito ${ }^{83}$.

La lógica que aplicó a este caso la SCJN es la misma que se ha reconocido en los tratados internacionales sobre desaparición forzada de personas: si bien el crimen no se considera imprescriptible, se deben fijar tiempos de prescripción prolongados. Este es el efecto que se logra cuando los plazos de prescripción empiezan a correr hasta que la persona es libertada (en el caso de la privación ilegal de la libertad) o encontrada (en el caso de la desaparición forzada de personas) $^{84}$.

Al poco tiempo, la Primera Sala de la SCJN resolvió otro tema de prescripción. En el Recurso de Apelación 1/2004 se resolvió sobre la prescripción del crimen de genocidio, imputado al ex Presidente Luis Echeverría Álvarez y otras personas. En este caso se resolvió que la Convención sobre Imprescriptibilidad no tiene efectos retroactivos, previos a la entrada en vigor para México. Al analizar la declaración interpretativa que se formuló, la SCJN señaló que el único efecto que tenía era ligar el tratado internacional con lo ya dispuesto en el artículo 14 constitucional que prohíbe la retroactividad de las leyes penales y de los tratados, por lo que no había nada novedoso en ello ${ }^{85}$. Por lo tanto, la imprescriptibilidad prevista en la Convención sobre Imprescriptibilidad no podría ser aplicada a hechos previos a 2002.

Por otro lado, la Primera Sala señaló que la prescripción solamente se puede interrumpir por disposiciones legales o constitucionales. En este caso, el Artículo 114 párrafo segundo prevé que los plazos de prescripción se interrumpen para ciertos funcionarios públicos (incluyendo el presidente y secretario) mientras se encuentren en su encargo ${ }^{86}$. La SCJN no dudo en aplicar esta reforma de 1985 de forma retroactiva, argumentando que la Constitución Federal se aplica retroactivamente, salvo disposición en contrario ${ }^{87}$.

En conclusión, el genocidio prescribía en 30 años; sin embargo, dado que el plazo de la prescripción se había interrumpido al momento de la impugnación, el crimen no había prescrito todavía.

A diferencia de lo argumentado en el caso Cavallo no se consideró la posibilidad de interrumpir la prescripción durante el tiempo en el que Echeverría Álvarez fue presidente. La Primera Sala optó por no pronunciarse sobre la viabilidad de iniciar una investigación penal cuando el

\footnotetext{
${ }^{81}$ Véase RATner, Steven R. y Abrams, Jason (2001), op. cit. nota 66, pp. 143 - 145. (Los Estados que han optado por no incluir la imprescriptibilidad de los crímenes internacionales pueden establecer una de dos estrategias nacionales: Ampliar los plazos de prescripción (aun retroactivamente) o plantear que la prescripción se interrumpió hasta que no haya sido posible establecer un juicio justo (fair trial).

82 Véase Recurso de Apelación 1/2003-PS, pp. $283-4$.

${ }^{83}$ Ibídem, p. 287.

${ }^{84}$ Véase Controversia Constitucional 33/2002. (Aunque en este caso no se planteó el tema de la prescripción de la desaparición forzada de personas, si se analizó como un crimen de naturaleza permanente, por lo que es aplicable del mismo criterio aquí expuesto.)

85 Véase Recurso de Apelación 1/2004-PS, pp. 89 - 90.

${ }^{86}$ Ibídem, pp. $169-171$.

87 Ibídem, pp. $178-180$.
} 
agente del Ministerio Público depende del Ejecutivo Federal ${ }^{88}$. Lo anterior con el argumento de que la prescripción no puede depender de un análisis fáctico.

En conclusión, la postura de México, del análisis de la legislación vigente y de la SCJN es que los crímenes internacionales son imprescriptibles con posterioridad a la entrada en vigor de la Convención sobre Imprescriptibilidad en 2002, en sintonía con la práctica internacional, aunque no con el texto del tratado.

También la práctica legislativa indica que la tortura y la desaparición forzada de personas son imprescriptibles. Sin embargo, siguiendo los criterios de la SCJN, solamente la desaparición forzada cometida con anterioridad a esa fecha puede también ser imprescriptible. En todos los demás casos, en respecto a la irretroactividad de la ley penal habrá que analizar si hubo interrupción de la prescripción. Esto es importante en el caso de la tortura, pues no se trata de un crimen permanente.

En todo caso, la laguna se encuentra con relación a los crímenes competencia de la CPI que no forman parte de la Convención sobre Imprescriptibilidad. Si bien el ECPI se ha ratificado, esto no ha generado una serie de reformas para incorporar los crímenes competencia de la CPI, como ha sucedido en otros países. No hay tipificación y, por consiguiente, tampoco disposiciones de imprescriptibilidad. Opera la regla general para calcular los plazos de prescripción y, en su caso, de su interrupción.

\section{Conclusiones}

La imprescriptibilidad de los crímenes internacionales no es una regla absoluta. Hacer cualquier afirmación al respecto implica señalar la conducta en particular y el tiempo de la entrada en vigor de la norma jurídica.

En el caso de los crímenes competencia de la CPI, queda claro que la imprescriptibilidad se aplica sin reservas a partir de la entrada en vigor del Estatuto de Roma. Es importante precisar que esta disposición solamente aplica para dicha jurisdicción internacional. No obstante, ha tenido un efecto en las jurisdicciones nacionales, pues al momento de implementar el ECPI los Estados han optado por establecer una regla de imprescriptibilidad para estos crímenes internacionales. Más allá de la discusión en torno a la obligación de establecer la imprescriptibilidad dentro del análisis de complementariedad, el efecto que ha tendido este tratado internacional en la modificación de las diversas legislaciones nacionales parece ser un mejor indicador del carácter consuetudinario de esta medida. En tanto exista un mayor número de legislaciones que prevean la implementación del Estatuto de Roma, mejor será el argumento en favor de la cristalización de la norma de costumbre internacional.

Es importante puntualizar que antes de la entrada en vigor del Estatuto de Roma, la imprescriptibilidad del genocidio, los crímenes de lesa humanidad y los crímenes de guerra solamente es aplicable a los Estados parte de cualquiera de las dos convenciones sobre imprescriptibilidad. Para aquellos Estados que hayan ratificado la Convención sobre Imprescriptibilidad sin reservas o declaraciones interpretativas, la medida puede tener efectos retroactivos. Para los Estados, como México, que hayan aclarado el carácter prospectivo del tratado, la medida será aplicable a partir de la fecha de entrada en vigor. También es importante recordar que solamente estarán

\footnotetext{
${ }^{88}$ Ibídem, pp. $150-151 ; 157-158$. 
sometidos a esta medida los crímenes internacionales señalados en dicho tratado, tomando en cuenta que hay avances en el Derecho penal internacional que no se han reflejado.

En el caso de las conductas individuales la situación es mucho más compleja. En el caso de la desaparición forzada de personas, no parece haber una regla de imprescriptibilidad aplicable. Sin embargo, al tratarse de un crimen de naturaleza permanente, es más fácil cumplir con la obligación de establecer plazos prolongados para la prescripción. En la medida en la cual hay cierta unanimidad en el sentido de que el cómputo para la prescripción empieza cuando la persona es encontrada es inevitable pensar que se trata de una imprescriptibilidad de facto, pues siempre se estará a plazos que pueden durar varias décadas, dependiendo de la legislación aplicable.

En el caso de la tortura, es donde hay mucho menos argumentos para sustentar una norma de imprescriptibilidad. Los tratados no la prevén, los estatutos de los tribunales híbridos es contradictoria entre sí y, a menos de que un Estado la implemente directamente, como el caso de México, no hay argumentos generalizados para establecer dicha norma. Si a esto se le agrega que la CorteIDH, órgano jurisdiccional que más ha pugnado por la imprescriptibilidad de la tortura, ha matizado su postura, se vuelve muy complicado afirmar la imprescriptibilidad de la tortura.

La actual postura de la CorteIDH es interesante y mucho más sofisticada que simplemente señalar la imprescriptibilidad de la tortura. Sujetar esta medida al criterio de debidas diligencias pretende establecer un equilibrio entre el combate a la impunidad y el debido proceso. Hay que recordar que en materia penal se ha justificado la prescripción en aras de un respeto a los derechos de defensa y debido proceso. Este nuevo criterio, es similar a la cosa juzgada fraudulenta y el interés de la justicia en el contexto del ECPI. Estas medidas obligan a hacer un análisis sobre la integridad de las investigaciones y los procesos. Si éstos son legítimos, es decir, no tienen la intención de sustraer a la persona de la acción de la justicia entonces no habrá forma de defender la imprescriptibilidad.

Esto lleva directamente a la última conclusión. Hasta ahora se ha planteado una discusión maniquea: hay o no hay prescripción. En este estudio se ha demostrado que la discusión es mucho más compleja y admite muchos matices. Existe más evidencia en el sentido de que se esté formulando una norma de costumbre internacional (que rechace la imprescriptibilidad) en el sentido de que en los casos de desaparición forzada, tortura y ejecuciones se establezcan periodos de prescripción prolongados. Esto se ha cristalizado con mayor claridad en el caso de la desaparición forzada de personas por su carácter permanente, pero puede ser aplicable a los otros dos crímenes internacionales.

En el caso de la tortura se puede retomar el concepto de debidas diligencias, el concepto de cosa juzgada fraudulenta y la postura de la SCJN para empezar a formar una norma de derecho consuetudinario que puede formularse así: En el caso de tortura los plazos de prescripción no empezarán a correr o se suspenderán mientras no haya condiciones fácticas (en esto la propues- 
ta se aparta de los señalado por la SCJN) o jurídicas para iniciar una investigación o proceso con las debidas diligencias.

Una propuesta en este sentido equivaldría a establecer plazos de prescripción prolongados. Como la tortura no es un crimen permanente no puede beneficiarse de la misma fórmula de la desaparición forzada, pero con un mecanismo como el propuesto se puede llegar al mismo resultado: el establecimiento de plazos prolongados para la prescripción.

Existe poca evidencia en el caso de las ejecuciones, pues los casos presentados normalmente han ocurrido en el contexto de masacres que implican la comisión de genocidio, crímenes de lesa humanidad o crímenes de guerra ${ }^{89}$. Sin embargo, la fórmula de plazo prolongado pudiera aplicarse también en estos casos.

Para avanzar en el tema es importante reconocer que los Estados no están dispuestos a aplicar medidas de imprescriptibilidad en todos los casos o en cualquier momento. Por lo tanto es importante dejar de pensar en la imprescriptibilidad como un absoluto.

Es importante considerar una emergente norma costumbre internacional de plazos prolongados, que ya se ha establecido en algunos tratados; a la par de medidas de interrupción de la prescripción (que pudieran tener el efecto de establecer plazos prolongados) para crímenes internacionales que se cometen de forma aislada.

\section{Fuentes}

Амвоs, Kai (2013), Treatise on International Criminal Law, Vol. I - Foundations and General Part, Oxford, Oxford University Press.

BIRzU, Bogdan (2015), "Considerations regarding the Non applicability of Statutory Limitations to Genocide, Crimes against Humanity and War Crimes", Acta Universitatis Danubius, Vol.11 No 3, Romania, Law Faculty of Danubius University of Galati.

Cryer, Robert, et al (2007), An Introduction to International Criminal Law and Procedure, Cambridge University Press.

Donde Matute, Javier (2010), "El concepto de impunidad: leyes de amnistía y otras formas estudiadas por la Corte Interamericana de Derechos humanos" en: Sistema Interamericano de Protección de los Derechos humanos y Derecho Penal Internacional, Vol. II, Montevideo, Konrad Adenauer Stiftung.

Der Wyngeart, Christine Van y Dugard, John (2002), "Non-Application of Statute of Limitations" en: The Rome Statute of the International Criminal Court: A Commentary, Vol. I (Antonio Cassese, Paola Gaeta, John R.W.D. Jones, eds), Oxford.

Gover, Sonja C. (2010), The European Court of Human Rights as a Pathway to Impunity for International Crimes, Canadá, Springer.

\footnotetext{
${ }^{89}$ Por ejemplo, puede hablarse de crímenes emblemáticos que fueron incorporados recientemente en el Estatuto de la Corte Penal Internacional, tales como el previsto en el artículo 8, párr.2, inciso a), numeral ii) La tortura o los tratos inhumanos, incluidos los experimentos biológicos; párr. 2, inciso b), numeral ix) Dirigir intencionalmente ataques contra edificios dedicados a la religión, la educación, las artes, las ciencias o la beneficencia, los monumentos históricos (...); y párr. 2, inciso b), numeral xxvi) Reclutar o alistar a niños menores de 15 años en las fuerzas armadas nacionales o utilizarlos para participar activamente en las hostilidades;
} 
MeIjer, Ernestine E. (2004), The Extraordinary Chambers in the Courts of Cambodia for Prosecuting Crimes Committed by the Khmer Rouge: Jurisdiction Organization, and Procedure of an Internationalized National Tribunal en Internationalized Criminal Courts - Sierra Leone, East Timor, Kosovo and Cambodia, (Cesare P.R. Romano, André Nollkaemper and Jann K. Kleffner eds.), International Courts and Tribunals Series, Oxford University Press.

Milanovic, Marko (2011), "Is the Rome Statute Binding on Individuals (And Why Should We Care)", Journal of International Criminal Justice, Vol. 9.

Miller, Robert H. (1971), “The Convention on the Non-Applicability of Statutory Limitations to War Crimes and Crimes Against Humanity”, American Society of International Law, Vol. 65, $\mathrm{N}^{\circ} 3$.

Mir Pius, Santiago (2011), Derecho Penal - Parte General, Barcelona, Editorial Reppertor.

PARra, Oscar (2012), "La jurisprudencia de la Corte Interamericana respecto a la lucha contra la impunidad: algunos avances y debates", Revista jurídica de la Universidad de Palermo, Año $13, \mathrm{~N}^{\circ} 1$.

Ratner, Steven R. y Abrams, Jason (2001), Accountability for Human Rights Atrocities in International Law, Oxford University Press.

G.A. Res 2583 (XXIV); G.A. Res 2712 (XXV); G.A. Res 2840 (XXVI); G.A. Res 3020 (XXVII); G.A. Res 3074 (XXVIII).

Schabas, William (2008), “Article 29", en: Commentary on the Rome Statute of the International Criminal Court, (Otto Triffterer ed) 2 ${ }^{\text {a }}$ Edición, C.H. Beck/Hart/Nomos.

Swart, Bert (2004), "Internationalized Courts and Substantive Criminal Law", en: Internationalized Criminal Courts - Sierra Leone, East Timor, Kosovo and Cambodia, (Cesare P.R. Romano, André Nollkaemper and Jann K. Kleffner eds.), International Courts and Tribunals Series, Oxford University Press

Roxin, Claus (1997), Derecho Penal - Parte General, Tomo I, Diego-Manuel Luzón Peña, Miguel Diaz y García Conlledo y Javier de Vicente Remesal (trads.), Madrid, Thomson / Civitas.

Vela Treviño, Sergio (1990), La prescripción en materia penal, $2^{\circ}$ edición, México, Trillas.

Villalpando, Waldo (2009): "El nuevo Derecho Internacional Penal los crímenes internacionales", Invenio, Vol 12, № 23, Argentina, Universidad del Centro Educativo Latinoamericano.

ZAHAR, Alexander y Sluiter, Göran (2008), Intenational Criminal Law, Oxford, Oxford University Press. 


\section{Casos:}

Cöeme and others vs. Belguim, Application Nos. 32492/96, Judgement, parr. 145

Explanatory Report to the European Convention on the Non-Applicability of Statutory Limitation to Crimes against Humanity and War Crimes, European Treaty Series No. 82, Estrasburgo, 25 enero 1974.

Prosecutor vs Gaddafi and Al-Senussi, Decision on the admissibility of the case against Saif Al-Islam Gaddafi, Pre-Trial Chamber I, ICC-01/11-01/11, 31 Mayo 2013.

Prosecutor v. Furundzija, IT-95-17/1-T, Judgment, 10 December 1998.

ECtHR, Abdülsament Yaman v. Turkey. European Court of Human Rights, Application no. 32446/96, 2 November 2004, párr 55; ECtHR, Mocanu and others v. Romania, Applications nos. 10865/09, 45886/07 and 32431/o8. 17, September 2014.

ECtHR, Korbely v. Hungary. Application no. 9174/o2, 19 September 2008.

ECtHR, Kolk and Kislyiy v. Estonia (dec.), Application no. 23052/04 by August Kolk.

ECtHR, Kononov c. Lettonie, Requête no 36376/04, 17 mai 2010.

CorteIDH, Caso Barrios Altos vs Perú. Fondo. Sentencia de 14 de marzo de 2001.

CorteIDH, Bulacio vs. Argentina. Fondo, reparaciones y costas. Sentencia de 18 de septiembre de 2003.

CorteIDH, Caso Albán Cornejo y otros vs. Ecuador, Fondo, reparaciones y costas. Sentencia de 22 de noviembre de 2007.

CorteIDH, Caso de la Masacre de La Rochela vs. Colombia. Fondo, reparaciones y costas. Sentencia de 11 de Mayo de 2007.

CorteIDH, Vera Vera y otra vs. Ecuador. Excepción preliminar, fondo, reparaciones y costas. Sentencia de 19 de mayo de 2011.

CorteIDH, Trujillo Oroza vs. Bolivia. Reparaciones y costas. Sentencia de 27 de febrero de 2002.

CorteIDH, Bueno Alves vs Argentina. Supervisión de cumplimiento de sentencia. Resolución de 5 de julio de 2011.

\section{Legislacion:}

Congo, Journal Officiel de la République Démocratique du Congo.

Croatia, Criminal Code Kazneni Zakon.

España, Ley Orgánica 10/1995, de 23 de noviembre, del Código Penal.

Estonia, Penal Code Passed 6 June 2001. 
Finlandia, The Criminal Code of Finland 39/1889, Chapter 8.

Guatemala, Iniciativa que dispone aprobar la ley de implementación del Estatuto de Roma de la Corte Penal Internacional.

Irland, International Criminal Court Act 2006.

Lithuania, Law on the approval and entry info foce of the criminal code, 26 september 2000 No. Viii-1968.

Panamá, Código Penal de la República de Panamá.

Paraguay, Proyecto de ley que implementa el Estatuto de Roma que crea la Corte Penal Internacional.

Perú, Ley que Regula los Delitos Contra el Derechos Internacional de los Derechos Humanos y el Derecho Internacional Humanitario.

Slovenia, Criminal Code (KZ-1).

The Netherlands, Act of 19 June 2003 containing rules on grave breaches of international humanitarian law (International Crimes Act). 